\title{
Antiretroviral resistance in individuals presenting therapeutic failure and subtypes of the human immunodeficiency virus type 1 in the Northeast Region of Brazil
}

\author{
Ana Maria Salustiano Cavalcanti ${ }^{*} /+$, Heloisa Ramos Lacerda*, Ana Maria de Brito**, \\ Sirleide Pereira, Daniela Medeiros, Suelene Oliveira***
}

\begin{abstract}
Laboratório Central da Secretaria de Saúde do Estado de Pernambuco, Praça Oswaldo Cruz, 50050-210 Recife, PE, Brasil *Curso de Pós-Graduação em Medicina Tropical, Universidade Federal de Pernambuco, Recife, PE, Brasil **Centro de Pesquisas Aggeu Magalhães, Recife, PE, Brasil ***Programa Nacional de DST/AIDS, Ministério da Saúde, Brasília, Brasil
\end{abstract}

This study aimed to analyze human immunodeficiency virus (HIV) mutation profiles related to antiretroviral resistance following therapeutic failure, and the distribution of HIV subtypes in the Northeast Region of Brazil. A total of 576 blood samples from AIDS patients presenting therapeutic failure between 2002 and 2004 were analyzed. The genotyping kit ViroSeq ${ }^{\circledR}$ was used to perform viral amplification in order to identify mutations related to HIV pol gene resistance. An index of $91.1 \%$ of the patients presented mutations for nucleoside reverse transcriptase inhibitors (NRTI), 58.7\% for non-nucleoside reverse transcriptase inhibitors (NNRTI), and $94.8 \%$ for protease inhibitors (PI). The most prevalent mutations were $184 \mathrm{~V}$ and $215 \mathrm{E}$ for NRTI, $103 \mathrm{~N}$ and $190 \mathrm{~A}$ for NNRTI. Most mutations associated with PIs were secondary, but significant frequencies were observed in codons $90(25.2 \%), 82(21.1 \%)$, and $30(16.2 \%)$. The resistance index to one class of antiretrovirals was $14 \%$, to two classes of antiretrovirals $61 \%$, and to three classes $18.9 \%$. Subtype B was the most prevalent (82.4\%) followed by subtype $F(11.8 \%)$. The prevalence of mutations related to NRTI and NNRTI was the same in the two subtypes, but codon analysis related to PI showed a higher frequency of mutations in codon 63 in subtype B and in codon 36 in subtype F. The present study showed that there was a high frequency of primary mutations, which offered resistance to NRTI and NNRTI. Monitoring patients with treatment failure is an important tool for aiding physicians in rescue therapy.

Key words: human immunodeficiency virus type 1 - resistance to drugs - genotyping - subtypes - Brazil

The use of antiretroviral drugs which started with AZT at the end of the $80 \mathrm{~s}$ (Fischl et al. 1987) was transformed through the use of highly active antiretroviral therapy (HAART) from 1996 onwards, and this brought in a period of great euphoria (Hammer et al. 1997). At that moment it seemed that the challenge of treating human immunodeficiency virus (HIV) infection had largely been solved. A significant decrease in morbidity and mortality rates due to AIDS was observed (Palella et al. 1998) even in Brazil, where universal distribution of antiretrovirals by the Ministry of Health began in 1991 . However, despite the success of this therapy, it was observed that some patients presented failure of the antiretroviral regimens, even in the case of the higher active ones (Ledergerber et al. 1999). As a result, the choice of subsequent therapies proved to be difficult, since such failure generally resulted in the emergence of resistance mutations that could even cause crossresistance between several antiretrovirals of the same drug class (Clavel \& Hance 2004). In this scenario, several studies

Financial support: Programa Nacional de DST/AIDS, Ministério da Saúde do Brasil

${ }^{+}$Corresponding author: a_salustiano@yahoo.com.br

Received 25 January $200 \overline{7}$

Accepted 17 September 2007 such as those of Viradapt (Europe), Gart (United States), Narval (France), Havana (Spain), and Avanti (Italy), assessed the benefit of genotyping tests as a tool for assisting in the therapeutic rescue of patients with treatment failure. These studies showed that, among patients with antiretroviral failure, the use of genotyping tests led to a greater effectiveness regarding medication change, in comparison with the empirical choices that were habitually made (Haubrich \& Demeter 2001). With regard to costs, a decrease in those related to medication was observed as a result to an earlier and correct treatment choice and particularly to the rational use of protease inhibitors (Chaix et al. 2000, Diaz 2004).

In Brazil, through the National STD/AIDS Program, the Ministry of Health implemented the National Genotyping Network (Renageno) from 2001 on. The network was composed of laboratories distributed along different country regions with capacity to carry out genotyping tests and also teams of doctors trained for interpreting these tests. The Central Public Health Laboratory of Pernambuco State (Lacen-PE) was responsible for tests in the states of Piauí, Ceará, Rio Grande do Norte, Paraíba, Pernambuco, and Alagoas; all of them localized in the Northeast Region of Brazil. The present study describes the frequency of resistance to the principal classes of antiretrovirals, the frequency of HIV-1 mutations associated with these medications, the prevalence of this virus subtypes in the Northeast region, and the differences in mutation frequency between the most prevalent subtypes, detected in samples from patients who underwent the genotyping test at Lacen-PE, between 2002 and 2004. 


\section{PATIENTS, MATERIALS AND METHODS}

Cases - All samples taken from individuals from the states of Piauí, Ceará, Rio Grande do Norte, Paraíba, Pernambuco, and Alagoas, who presented therapeutic failure to antiretrovirals and underwent HIV genotyping tests at Lacen-PE between January, 2002 and December, 2004, were included in the study. Therapeutic failure was defined as the elevation of viral load to above 5000 copies $/ \mathrm{ml}$ or a rise in viral load of $0.5 \log$ or more. The participants received relevant information and signed a consent form. This study was part of the Ministry of Health's original Renageno project, which was approved by the National Ethics and Research Commission (Protocol no. 2857).

HIV-1 resistance genotyping determination - The ViroSeq ${ }^{\mathrm{TM}}$ HIV-1 Genotyping System (Celera Diagnostic, Abbott Laboratories, US) was used to identify the resistance-associated mutations in the HIV-1 polymerase ( $\mathrm{pol}$ ) gene. The methodology included isolation and purification of plasma viral RNA, followed by cDNA syn- thesis and genomic amplification by polymerase chain reaction (PCR) assay of the HIV-1 pol fragment (reverse transcritase-PCR and PCR module), spanning the entire protease (PR) gene and approximately two thirds of the RT gene. The amplified PCR products were sequenced using the BigDye Terminator sequencing chemistry (Sequencing Module - Big Dye v.2.0), and they were analyzed on an ABI Prism 3100 Genetic Analyzer (Applied Biosystems, US), coupled to the DNA sequencing analysis software. Mutation resistance profiles were classified according to the International AIDS Society consensus (D'Aquilla et al. 2002). To determine the HIV-1 genetic subtypes, all sequences were analyzed using the Stanford Sequence Resistance Database (http:// hivdb.stanford.edu).

\section{RESULTS}

A total of 576 samples were collected, but the mutation analysis was performed on only 516 samples, since $21(3.6 \%)$ were mislaid, $37(6.4 \%)$ were not amplified and two $(0.35 \%)$ did not show any mutations. The

TABLE

Demographic, immunological, and virological data from all individuals, and in relation to the most prevalent subtypes

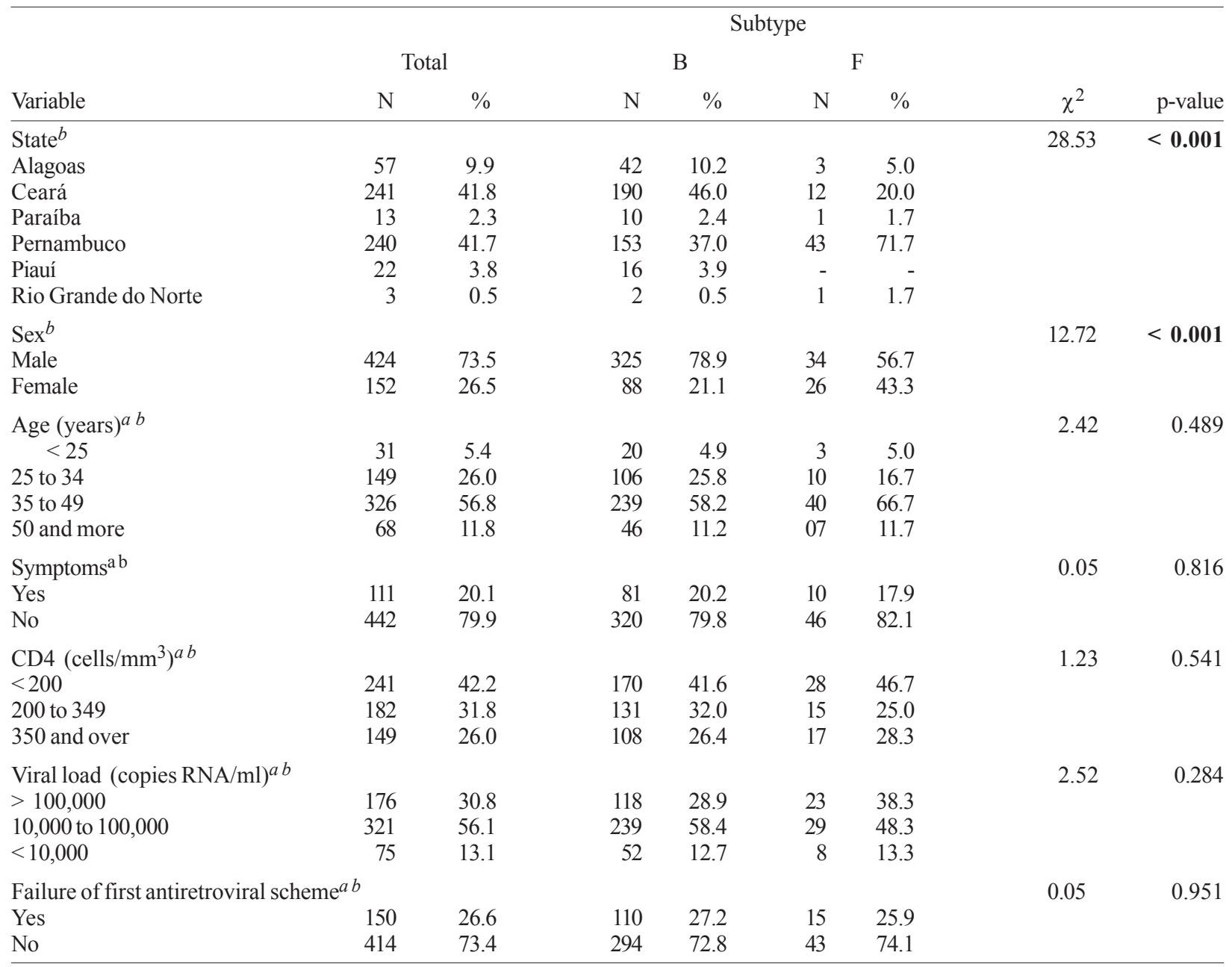

$a$ : the difference between the general total and the total for each variable is due to missing information; $b$ : the difference between the general total and the total for each subtype is due to differences in the number of samples obtained and the number of samples analyzed for subtypes. 
sociodemographic characteristics of the 516 patients included in the study are shown in the Table. Most of the patients were asymptomatic, with a mean $\mathrm{T} \mathrm{CD}^{+}$lymphocyte count of 268 , and around $69 \%$ presented a viral load lower than 100,000 copies/ml. Most cases had already used more than one antiretroviral treatment.

At least one main mutation for nucleoside reverse transcriptase inhibitors (NRTIs) was found in $89.1 \%$ of the samples; for non-NRTIs (NNRTI), in 55.4\%; and for protease inhibitors (PIs), in $49.4 \%$. The most frequent mutations related to NRTIs occurred in codons 184
(66\%), $215(61.5 \%)$, and 41(47.9\%). Other mutations in codons associated with thymidine analog resistance mutations (TAMs) had a significant frequency: 67N, 70R, $210 \mathrm{~W}$, and $219 \mathrm{Q} / \mathrm{E} / \mathrm{N}$. Among the mutations associated with NNRTIs, the most frequent were 103 (62\%), 190 (38.7\%), and 181 (29.2\%) (Fig. 1). Most mutations associated with PIs were secondary, but significant frequencies were observed in codons $90(25.2 \%), 82$ (21.1\%), and 30 (16.2\%) (Fig. 2).

A total of $14.1 \%$ of the patients presented resistance to one class of antiretrovirals; $61.4 \%$, to two classes; and

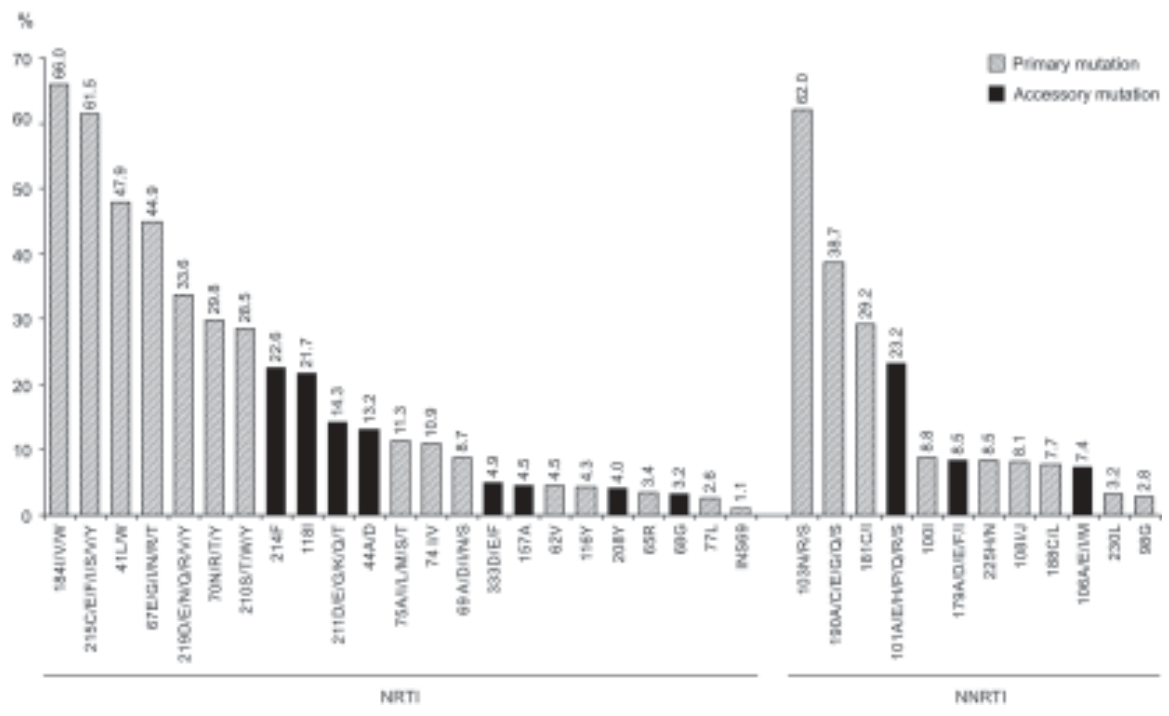

Fig. 1: percentage distribution of primary and accessory mutations associated with resistance to nucleoside analog reverse transcriptase inhibitors (NRTIs) and non-NRTIs (NNRTIs). Northeastern Region, 2002 to 2004.

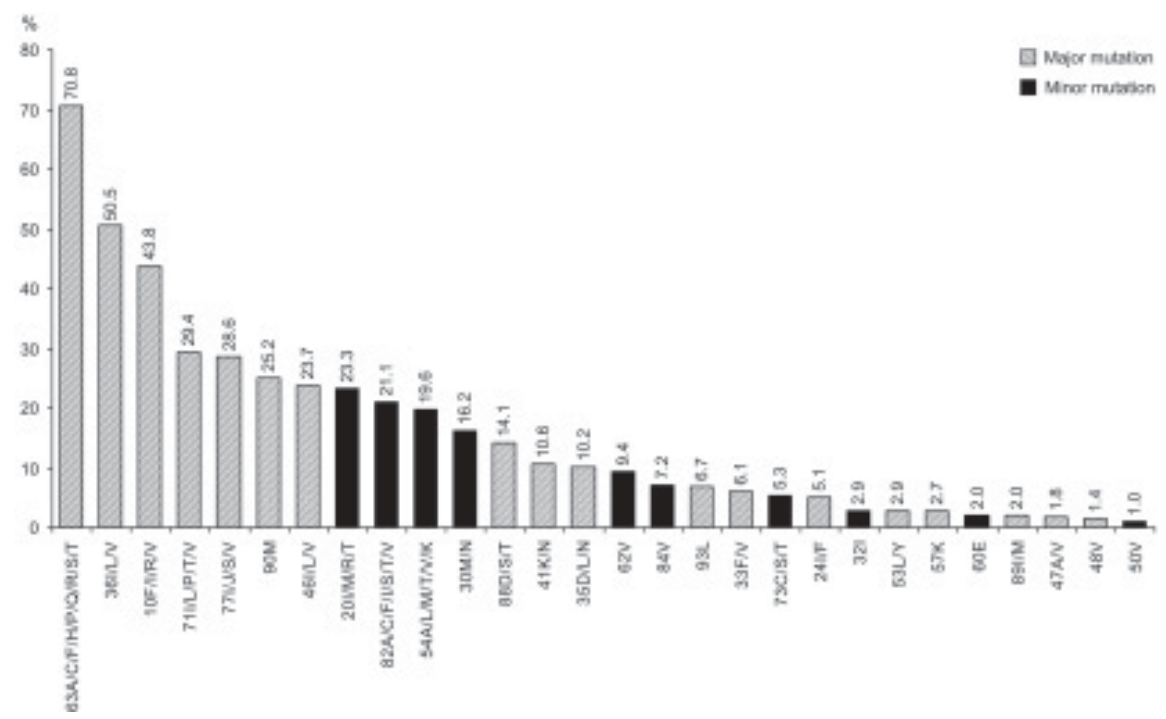

Fig. 2: percentage distribution of major and minor mutations relating to protease inhibitors. Northeastern region, 2002 to 2004. 
$18.9 \%$, to three classes of these drugs. Only $5.4 \%$ of the patients presented no resistance to any antiretroviral drug. With regard to the number of therapeutic regimens utilized, it was found that $26.6 \%$ had used one regimen; $30.3 \%$, had used two; $20.5 \%$, three; $12 \%$, four; and $10.6 \%$, five or more. Analysis of the mutations, according to antiretroviral class showed that the mean number of mutations had a direct relationship with the number of regimens utilized, and that this association was statistically significant in Pearson's correlation $(p<0.05)$.

From the 502 samples analyzed for subtypes, the most prevalent subtype was B ( $82.4 \%)$, followed by F (11.8\%), and recombinant subtypes $\mathrm{B} / \mathrm{D}$ and $\mathrm{B} / \mathrm{F}(4.6 \%)$. Only 5 (1\%) of the samples were subtype $C$ and one was subtype $\mathrm{D}(0.2 \%)$. The distribution of subtypes per state is presented in Fig. 3. Subtypes B and F accounted for $94.2 \%$ of the subtypes circulating in the region, and these were compared with each other regarding the patients' characteristics (Table).

The comparison of subtype $\mathrm{F}$ prevalence between Ceará and Pernambuco, regions with the highest number of samples, has shown a significant difference in the distribution of this subtype: in Pernambuco, subtype F occurred in $43(21.9 \%)$ patients, while in Ceará this subtype was detected in only $12(5.9 \%)$ patients, with a significant difference $(\mathrm{p}<0.01)$ (data not shown in the Table). A greater prevalence of subtype $\mathrm{F}$ has been detected among women: $26(22.8 \%)$ women compared to $34(9.5 \%)$ men $(\mathrm{p}<0.01)$.

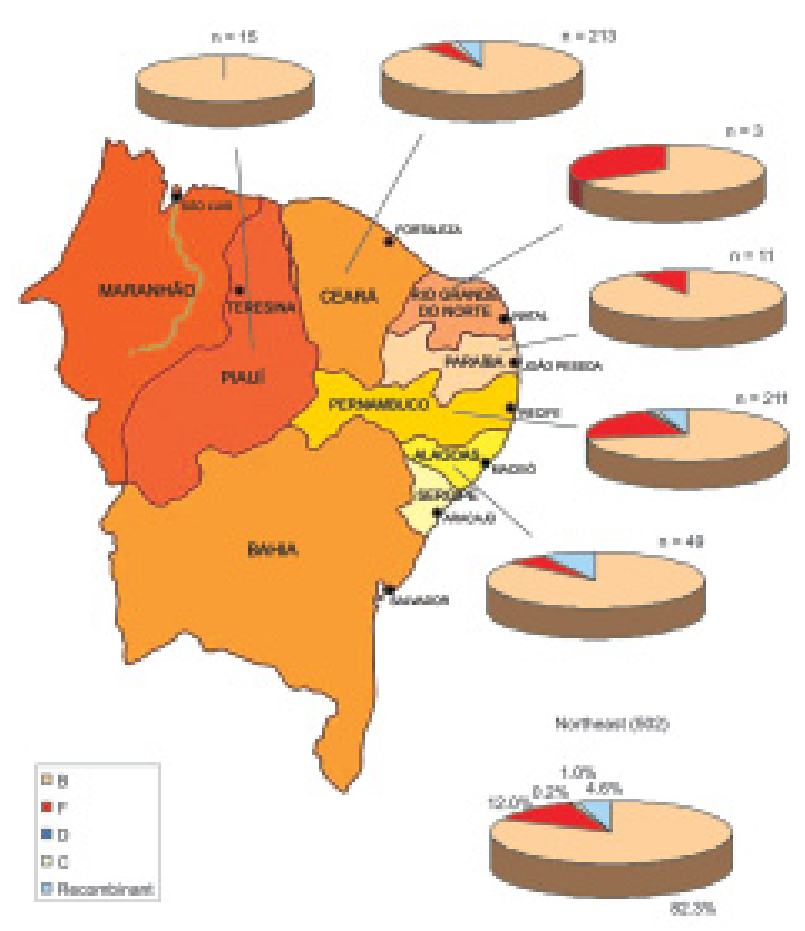

Fig. 3: geographic distribution of human immunodeficiency virus type-1 subtypes in the Northeast Region, 2002 to 2004.
Comparing the mutations related to the three classes of antiretrovirals in subtypes B and F, no statistically significant differences were observed, and the percentages were very close to those identified in the general analysis of mutations. Figs 4 and 5 present the prevalence of mutations in the most frequent subtypes (B and F) and correlate them with the NRTI, NNRTI, and PI regimens. Analyzing the most prevalent mutations for NRTIs, it was observed that mutation in codon 211 was more frequent in subtype $\mathrm{F}$ than in $\mathrm{B}$, and this difference was statistically significant $(p=0.0001)$. The opposite was observed with mutation 210 , which was more prevalent in subtype B than in F $(p=0.004)$. Fig. 4 also presents some mutations found in subtype B that were not shown in F (codons 65, 77, 116, 118, and 151).

The prevalence of mutations related to NNRTIs was similar in the two subtypes, except for mutations in codon 110 , which occurred only in subtype $F$, and in codon 98 , in subtype B.

There were statistically significant differences in the prevalence of mutations associated with PIs in the two subtypes, in relation to codons 35,36 , and $63(\mathrm{p}=0.000)$, since mutations in the first two were more prevalent in subtype $\mathrm{F}$, and in the third, in subtype $\mathrm{B}$. The presence of mutations in codon 20 was more frequent in subtype $\mathrm{F}(\mathrm{p}=$ $0.000)$, and in codon 77, in subtype B ( $\mathrm{p}=0.001)$ (Fig. 5).

\section{DISCUSSION}

The present study showed an uneven distribution in the number of samples sent by each state. Samples from Ceará and Pernambuco prevailed, probably due to the larger population of these two states, with a greater occurrence of AIDS cases. Most patients were asymptomatic, with a great chance of benefiting from rescue treatment.

The frequency of mutations was very high for all classes of antiretrovirals, which was expected for patients who had already undergone different antiretroviral regimens. Predominantly, primary mutations were associated with NRTIs and NNRTIs, and secondary mutations with PIs. Resistance to two drug classes occurred in $61.4 \%$ of the cases, and resistance to three classes was seen in $18.9 \%$ of them. Studies conducted in São Paulo by Sucupira et al. (2001) and Munerato et al. (2005) demonstrated a lower frequency of resistance for two classes of antiretrovirals, namely, $42.2 \%$ and $42.9 \%$, respectively; and higher rates of resistance to three drug classes (36.8\% and $46.5 \%$, respectively). Data suggest that multiresistance to antiretrovirals follows the historical sequence of the use of antiretrovirals, which started earlier and in a more comprehensive way in the Southeast Region (Brito el al. 2005).

The profile of mutations observed in this study presents similarities with other Brazilian studies. The most prevalent primary mutation associated with NRTIs occurred in codon $184(66 \%)$, similar to what was found in São Paulo (64\%) by Rodrigues et al. (2005), and in Rio de Janeiro (67\%) by Couto-Fernandez et al. (2005). Mutation in codon 184 is related to high resistance to lamivudine, and is the first mutation to emerge when this 


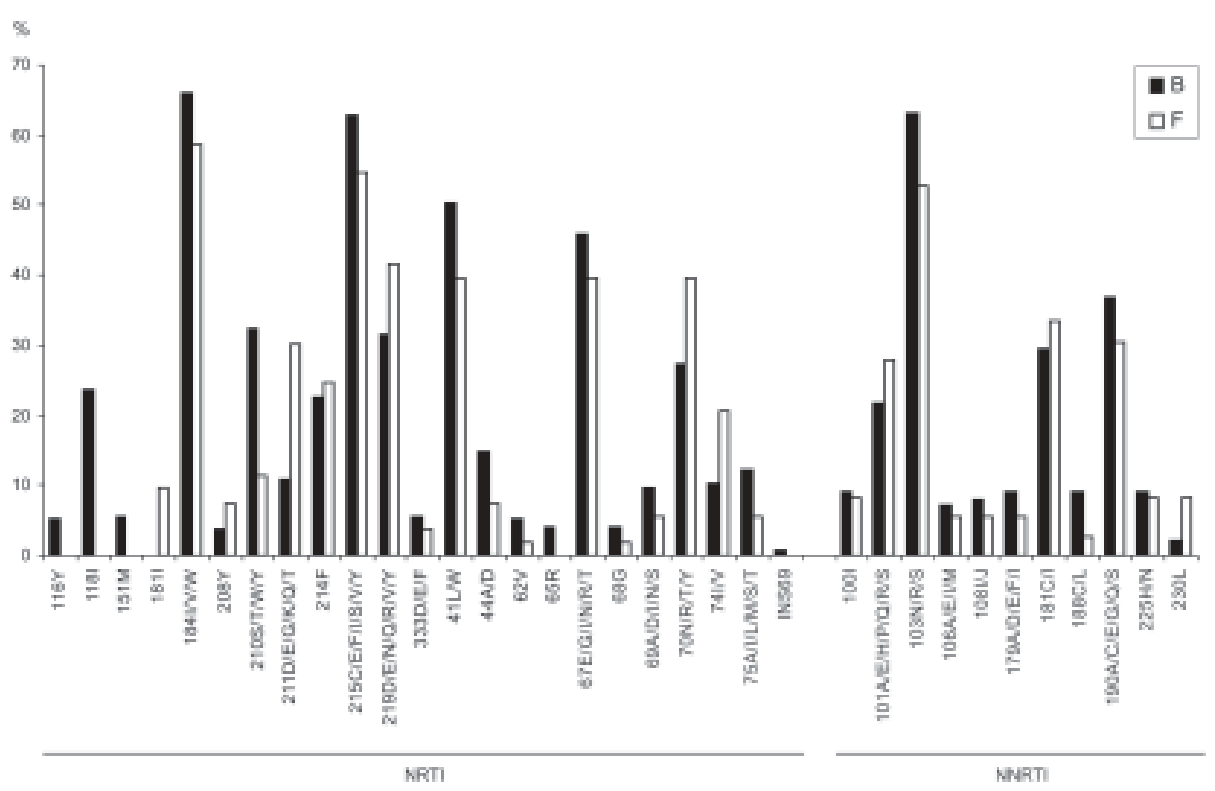

Fig. 4: percentage distribution of primary and accessory mutations associated with resistance to nucleoside analogue reverse transcriptase inhibitors (NRTIs) and non-NRTIs (NNRTIs), in relation to subtypes B and F. Northeastern region, 2002 to 2004.

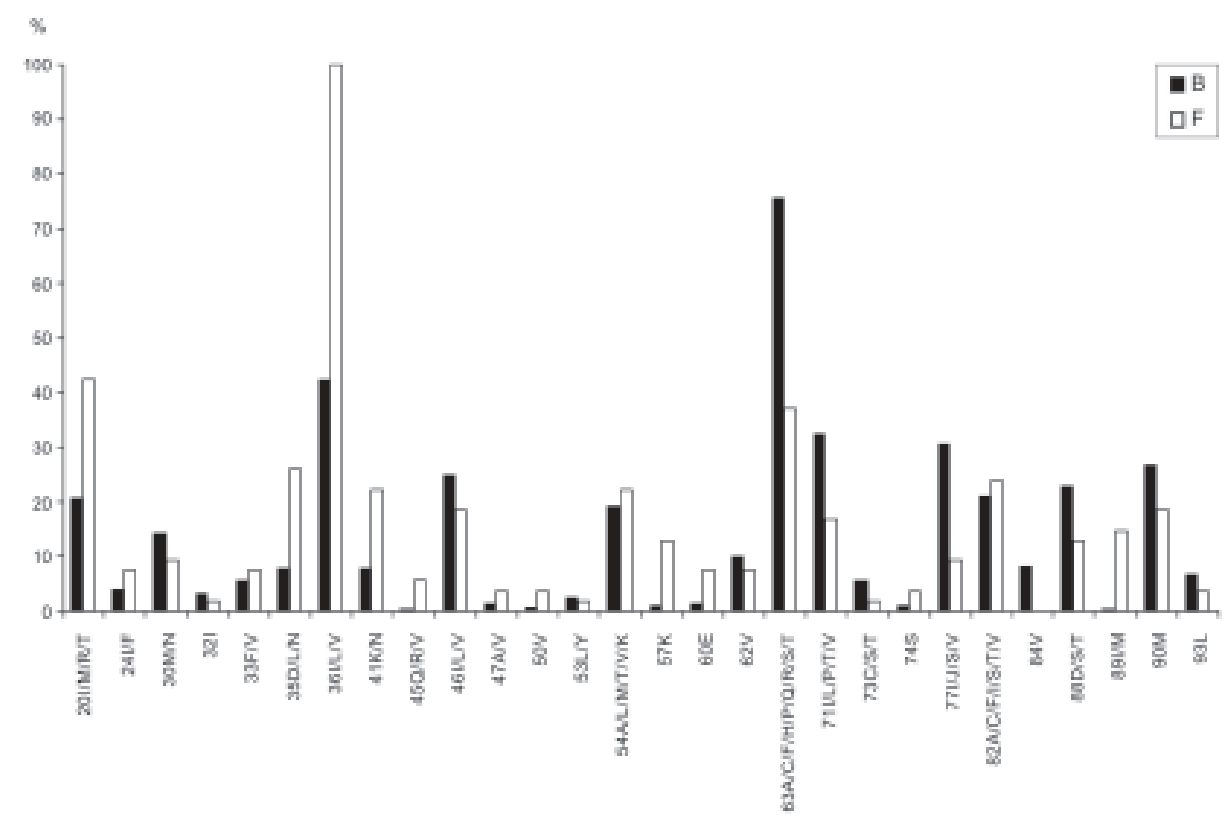

Fig. 5: percentage distribution of major and minor mutations associated with resistance to protease inhibitors, in relation to subtypes B and $\mathrm{F}$. Northeastern region, 2002 to 2004.

medication takes part of a powerful antiretroviral regimen that fails. Lamivudine also has a critical role in treating hepatitis B virus chronic hepatitis in AIDS patients, being used in almost $70 \%$ of patients with this co-infection in the study of Sucupira et al. (2006). The present study also revealed a high prevalence of mutations associated with thymidine (TAMs) in codons $41,67,70,210$, 215 , and 219 . These mutations may lead to a varying de- gree of cross-resistance between nucleoside analogs and represent a significant obstacle to obtaining rescue regimens capable of effectively controlling the viral load (Clavel \& Hance 2004). The K65R mutation, which is selected by abacavir or tenofovir, occurred in fewer than $3.4 \%$ of the individuals, probably due to their recent introduction into the Brazilian consensus for antiretroviral use (Brazilian Ministry of Health 2004). 
The frequency of mutations that confer resistance to NNRTIs in the present study was similar to that found in the studies of Couto-Fernandez et al. (2005) and Rodrigues et al. (2005). The most frequent mutation occurred in codon $103(62 \%)$, which is usually selected through therapy using efavirez and, occasionally, using nevirapine, and it confers a high level of resistance to all medications in this class. This finding probably is due to the fact of selecting efavirez as the first-choice drug for starting antiretroviral therapy, in accordance with the Brazilian consensus for antiretroviral use for many years. Mutation 190, which generally appears after ineffective prolonged therapy using NNRTIs (Diaz 2004), occurred in $38.7 \%$ of the cases. Mutation 181, which is generally selected by nevirapine, occurred only in $29.2 \%$ of the patients.

Analysis of the mutations associated with PIs showed a greater prevalence of secondary mutations in codons 63,36 , and 10 . The sum of the secondary mutations may facilitate the emergence of resistance to PIs, in a slow and gradual process that brings results with clinical significance (Clavel \& Hance 2004, Diaz 2004). With regard to primary mutations associated with this drug class, a prevalence of $25.5 \%$ was found in codon 90 , followed by $23.7 \%$ in codon $46(23.7 \%)$ and $21.1 \%$ in codon 82 . The mutation in codon 90 is generally selected by saquinavir and nelfinavir, and causes resistance to most PIs. Mutation 46 generally accumulates during the failure of most PIs, thereby causing a gradual increase in resistance levels, while mutation 82 emerges at an early stage of failure, frequently through indinavir and ritonavir (Diaz 2004).

Several studies have mapped out the circulation of HIV-1 subtypes in Brazil (Soares et al. 2003, Cerqueira et al. 2004, Pires et al. 2004, Couto-Fernandez et al. 2005, Rodrigues et al. 2005, Barreto et al. 2006). The study by Brindeiro et al. (2003) showed a predominance of subtype B $(64.9 \%)$, followed by C in $22.8 \%$ of the samples, and $\mathrm{F}$ in $11.8 \%$. Out of a total of 409 samples, only 48 were from Northeast Brazil, with predominance of samples from Ceará. In the same study, a significant regional variation in the circulation of subtypes $\mathrm{C}$ and $\mathrm{F}$ was observed. While subtype $\mathrm{C}$ circulated predominantly in the Southeast and Southern Regions, subtype F was more frequent in the Central-western and Northern Regions. The present study, which included 502 samples, demonstrated that subtype B had the greatest circulation, followed by subtype F, and few cases of subtype C, thus corroborating data from the mentioned study, regarding the Northeast Region.

The study showed a higher proportion of subtype $\mathrm{F}$ in Pernambuco (21.9\%) than in Ceará, where only 5.6\% of the samples belonged to this subtype. Three other works obtained very similar results to the present study: Medeiros et al. (2006) analyzed samples from Pernambuco alone and found a frequency of $22.6 \%$ for subtype F, while Gadelha et al. (2003) showed a frequency $2.7 \%$ for this subtype in Ceará and Couto-Fernandez et al. (1999) showed a frequency of only $3 \%$ for subtype $\mathrm{F}$ (3\%) in Salvador, Bahia, related only with injection drug users. This indicates intra-regional variations in the cir- culation of viral subtypes which are not fully understood. Two hypotheses may explain such differences: an earlier entry of subtype F in Pernambuco, if compared to other states from Northeast Region, particularly Ceará and Bahia, or different routes of propagation of the HIVinfection throughout the region.

Another difference between subtypes B and $\mathrm{F}$ was their association with gender. While $81 \%$ of the patients with subtype B were men, $43.3 \%$ of the patients with subtype $\mathrm{F}$ were women. This finding was also detected in Argentina (Masciotra et al 2000, Ávila et al. 2002) and Chile (Rios et al. 2005). There is no consensus whether this occurs due to a suspected major tropism of non-B subtypes of HIV to Langerhan's cells found in vaginal mucosa (Soto-Ramirez et al. 1996) or to the late introduction of subtype F in Brazil (Bello et al. 2006), concomitantly with the more recent entry of women in the Brazilian epidemic (Brito et al. 2005).

The mutations related to antiretroviral failure showed some differences between subtypes B and F. The mutations associated with NRTIs occurred most frequently in codon 211, in subtype F; while the mutation in codon 210 was more prevalent in subtype B. On the other hand, for mutations associated with PIs, differences occurred in codons 35,36 , and $63(\mathrm{p}=0.0000)$, so that the first two were revealed only in subtype $F$ and the third, in subtype B. It should be emphasized that the mutation in codon 20 was more frequent in subtype $\mathrm{F}$ and in codon 77 , in subtype B. This corroborates data found in Renageno samples, in studies in Federal District, Rio de Janeiro and São Paulo (Cerqueira et al. 2004, CoutoFernandez et al. 2005, Rodrigues et al. 2005). These findings may reinforce the hypothesis that subtypes B and $\mathrm{F}$ respond by producing different mutations at the time of failure of the antiretroviral treatment, particularly with regard to PIs. However, because the latter differences occurred mainly as secondary mutations, there is an intense debate about whether they might result in different levels of resistance to antiretrovirals (Accetturi et al. 2000, Frater 2002, Pillay et al. 2002, Holquin et al. 2004, Bocket et al. 2005, Geretti 2006, Vergne et al. 2006). Follow-up of therapeutic responses to rescue regimens may help to realize the real significance of the different mutations produced by distinct viral subtypes.

\section{REFERENCES}

Accetturi CA, Pardini R, Novaes Pinto GH, Turcato Jr G, Lewi DS, Diaz RS 2000. Effects of CCR5 genetic polymorphism and HIV1 subtype in antiretroviral response in Brazilian HIV-1-infected patients. J Acquir Immune Defic Syndr 24: 399-400.

Avilla MM, Pando MA, Carrion G, Salomon H, Carrillo MG, Sanchez J, Maulen S, Hierholzer J, Marinello M, Negrete M, Russel KL, Carr JK 2002. Two HIV-1 epidemics in Argentina: different genetic subtypes associated with different risk groups. J Acquir Immune Defic Syndr 29: 422-426.

Barreto CC, Nishyia A, Araujo LV, Ferreira JE, Bush MP, Sabino EC 2006. Trends in antiretroviral drug resistance and clade distributions among HIV-1 infected blood donors in São Paulo, Brazil. J Acquir Immune Defic Syndr 41: 338-341.

Bello G, Guimarães ML, MorgadoMG 2006. Evolutionary history of 
HIV-1 subtype B and F infection in Brazil. AIDS 20: 763-768.

Bocket L, Cheret A, Deuffic-Burban S, Choisy P, Gerard Y, de la Tribonniere X, Viget N, Ajana F, Goffard A, Barin F, Mouton Y, Yazdanpanah Y 2005. Impact of human immunodeficiency virus type 1 subtype on first-line antiretroviral therapy effectiveness. Antivir Ther 10: 247-254.

Brazilian Ministry of Health, National Program of STD/AIDS 2004. Consensus for the treatment of adults and adolescents with HIV infection. Brasília, $120 \mathrm{pp}$.

Brindeiro R, Diaz RS, Sabino EC, Morgado MG, Pires IL, Brigido L, Dantas MC, Barreira D, Teixeira PR, Tanuri A and the Brazilian Network for Drug Resistance Surveillance 2003. Brazilian Network for HIV Drug Resistance Surveillance (HIV-BResNet): a survey of chronically infected individuals. AIDS 17: 1063-1069.

Brito AM, Castilho EA, Szwarchwald CL 2005. Regional patterns of the temporal evolution of the AIDS epidemic in Brazil following the introduction of antiretroviral therapy. Braz J Infect Dis 9: 9-19.

Cerqueira DM, Amorim RM, Silva RR, Camara GN, Brigido MM, Martins CR 2004. Antiretroviral resistance and genetic diversity of human immunodeficiency virus type 1 isolates from the Federal District, Central Brazil. Mem Inst Oswaldo Cruz 99: 877-882.

Chaix C, Holtezer C, Phillips KA, Durand-Zaleski I, Stansell J 2000. HIV-1 drug resistance genotyping. A review of clinical and economic issues. Pharmacoeconomics 18: 425-433.

Clavel F, Hance AJ 2004. HIV drug resistance. $N$ Eng J Med 350: 1023-1035.

Couto-Fernandez JC, Morgado MG, Bongertz V, Tanuri A, Andrade T, Brites C, Galvão-Castro B 1999. HIV-1 subtyping in Salvador, Bahia, Brazil: a city with African sociodemographic characteristics. J Acquir Immune Defic Syndr 22: 288-293.

Couto-Fernandes JC, Silva-de-Jesus C, Veloso VG, Rachid M, Gracie RSG, Chequer-Fernandez SL, Oliveira SM, ArakakiSanchez D, Chequer PJN, Morgado MG 2005. Human immunodeficiency virus type 1 genotyping in Rio de Janeiro, Brazil: assessing subtype and drug-resistance associated mutations in HIV-1 infected individuals failing highly active antiretroviral therapy. Mem Inst Oswaldo Cruz 100: 73-78.

D'Aquilla RT, Schapiro JM, Brun-Vézinet F, Clotet B, Conway B, Demeter LM, Grant RM, Johnson VA, Kuritzes DR, Loveday C, Shafer RW, Richmann DD, International AIDS Society-USA 2002. Drug resistance mutations in HIV-1. Top HIV Med 10: 21-25.

Diaz RS 2004. Guia para o Manuseio de Testes de Resistência Anti-retroviral no Paciente Infectado pelo HIV-1, Abbott, São Paulo, 86 pp.

Fischl MA, Richman DD, Grieco MH, Gottlieb MS, Volberding PA, Laskin OL, Leedom JM, Groopman JE, Mildvan D, Schooley RT 1987. The efficacy of azidothymidine (AZT) in treatment of patients with AIDS and AIDS-related complex. A double-blind, placebo-controlled trial. N Engl J Med 317: 185-191.

Frater J 2002. The impact of HIV-1 subtype on the clinical response on HAART. J HIV Ther 7: 92-96.

Gadelha SR, Shindo N, Cruz, JNM, Morgado MG, Galvão-Castro B 2003. Molecular epidemiology of human immunodeficiency vírus-1 in the state of Ceará, Northeast, Brazil. Mem Inst Oswaldo Cruz 98: 461-464.

Geretti AM 2006. HIV-1 subtypes: epidemiology and significance for HIV management. Curr Opin Infect Dis 19: 1-7.

Hammer SM, Squires KE, Hughes MD, Grimes JM, Demeter LM, Currier JS, Eron JJJr, Feinberg JE, Balfour HHJr, Deyton LR, Chodakewitz JA, Fischl MA 1997. A controlled trial of two nucleoside analogues plus indinavir in persons with human immunodeficiency virus infection and CD4 cell counts of 200 per cubic millimeter or less. AIDS Clinical Trials Group 320 Study Team. $N$ Eng J Med 337: 725-733.

Haubrich R, Demeter L 2001. International perspectives on antiretroviral resistance. Clinical utility of resistance genotyping: retrospective and prospective data supporting use and current recommendations. J Acquir Immune Defic Syndr 26: S51-S59.

Holquin A, Paxinos E, Hertogs K, Womac C, Soriano V 2004. Impact of frequent natural polymorphisms at the protease gene on the in vitro susceptibility to protease inhibitors in HIV-1 non-B subtypes. J Clin Virol 31: 215-220.

Ledergerber B, Egger M, Opravil M, Telenti A, Hirschel B, Battegay M 1999. Clinical progression and virological failure on highly active antiretroviral therapy in HIV-1 patients: a prospective cohort study. Lancet 353: 863-868.

Masciotra S, Livellara B, Belloso W, Clara L, Tanuri A, Ramos AC, Baggs J, Lal R, Pieniazek D 2000. Evidence of a high frequency of HIV-1 subtype $\mathrm{F}$ infections in a heterosexual population in Buenos Aires, Argentina. AIDS Res Hum Retroviruses 16: 1007-1014.

Medeiros LB, Lacerda HR, Cavalcanti AMS, Albuquerque MFPM 2006. Primary resistance of human immunodeficiency virus type 1 in a reference center in Recife, Pernambuco, Brazil. Mem Inst Oswaldo Cruz 101: 845-849.

Munerato P, Andreo SM, Sucupira MC, Mamede S, Mota G, Sá Filho D, Cavalieri E, Arakaki D, Marins JRP, Diaz RS 2005. Patterns of HIV-1 genotypic antiretroviral resistance in clinical practice: a survey of the Brazilian network for genotypic resistance. In Abstracts of the 3rd IAS Conference of HIV pathogenesis and treatment, Rio de Janeiro, Brazil. International Aids Society, Geneva, p. 36.

Palella Jr FJ, Delaney KM, Moorman AC, Loveless MO, Further J, Satten GA, Ashman DJ, Holmber SD 1998. Declining morbidity and mortality among patients with advanced human immunodeficiency virus infection. Outpatient study investigators. $N$ Eng J Med 338: 853-856.

Pillay D, Walker AS, Gibb DM, Rossi A, Kaye S, Ait-Khaled M 2002. Impact of human immunodeficiency virus type 1 subtypes on virologic response and emergence of drug resistance among children in the Paediatric European Network for Treatment of AIDS (PENTA) 5 trial. J Infect Dis 186: 617-625.

Pires IL, Soares MA, Speranza FA, Ishii SK, Vieira MCG, Gouvêa MIFS, Guimarães MAAM, Oliveira FE, Magnanini MMF, Brindeiro RM, Tanuri A 2004. Prevalence of human immunodeficiency virus drug resistance mutations and subtypes in drug-naïve, infected individuals in the Army Health Service of Rio de Janeiro, Brazil. J Clin Microbiol 42: 426-430.

Rios M, Fernandez J, Jaramillo P, Paredes V, Sanchez JL, Laguna-Torres VA, Carr JK, Ramirez E 2005. Molecular epidemiology of HIV type 1 in Chile: differential geographic 
and transmission route distribution of $\mathrm{B}$ and $\mathrm{F}$ subtypes. AIDS Res Hum Retroviruses 21: 835-840.

Rodrigues R, Vazquez CMP, Colares JK, Custodio RM, Bonasser Filho F, Souza LR, Gianna MC, Marques CCA, Brigido LFM 2005. Antiretroviral resistance mutations in human immunodeficiency virus type 1 infected patients enrolled in genotype testing at the Central Public Health Laboratory, Sao Paulo, Brazil: preliminary results. Mem Inst Oswaldo Cruz 100: 97-102.

Stanford sequence resistance database 2006. Available at $<$ http:/ /hivdb.stanford.edu>; accessed 15 May 2006.

Soares EAJM, Santos RP, Pellegrini JA, Sprinz E, Tanuri A, Soares M 2003. Epidemiologic and molecular characterization of human immunodeficiency virus type 1 in Southern Brazil. $J$ Acquir Immune Defic Syndr 34: 520-526.

Soto-Ramirez LE, Renjifo B, McLane MF, Marlink R, O’Hara
C, Sutthent R 1996. HIV-1 Langerhans' cell tropism associated with heterosexual transmission of HIV. Science 271: 1291-1293.

Sucupira MVF, Mello FCA, Santos EA, Niel C, Rolla VC, Arabe J, Gomes SA 2006. Patterns of hepatitis B virus infection in Brazilian human immunodeficiency virus infected patients: high prevalence of occult infection and low frequency of lamivudine resistant mutations. Mem Inst Oswaldo Cruz 101: 655-660.

Sucupira MC, Souza IE, Costa LJ, Scheinberg MA, Diaz RS 2001. Antiretroviral treatment failure and HIV-1 genotypic resistance in São Paulo, Brazil. Antivir Ther 6: 263-264.

Vergne L, Stuyver L, Van Houtte M, Butel C, Delaporte E, Peeters M 2006. Natural polymorphism in protease and reverse transcriptase genes and in vitro antiretroviral drug susceptibilities of non-B HIV-1 strains from treatment-naïve patients. $J$ Clin Virol 36: 43-49. 